\title{
Comment 12.1
}

PHILIPPE KUHUTAMA MAWOKO

Africa has become an investment magnet thanks to its general economic performance as measured by a continuous improvement of its gross domestic product (GDP) and its population dynamics. Africa's GDP increased by 3.5 percent in 2018, about the same as in 2017 and up from 2.1 percent in 2016. This growth is projected to accelerate to 4.0 percent by the end of 2019 and 4.1 percent in 2020. ${ }^{1}$ Projections of population growth predict that the African population is likely to reach 1.7 billion by $2030 .^{2}$ These prospects have created an environment in which foreign firms and development partners are bound to interact with local firms and institutions. This has led to a complex and crowded policy environment that, if properly managed, will lead to good business outlooks, employment, and well-being for the African population.

In this space, technology and knowledge transfer will undoubtedly play a pivotal role in sustaining these undertakings. Consequently, relevant metrics will be required to produce evidence on which better policy can be made. Metrics will also facilitate better understanding and management of the complex patterns and interrelationships that will likely emerge. So, knowledge needs to be acquired, stored, created, disseminated, and improved on or added into existing knowledge. To that end, we welcome the chapter by Anthony Arundel and Nordine Es-Sadki, on which we are pleased to comment from an African perspective.

\section{STISA's Call for Knowledge Transfer Metrics}

The African Union adopted its current Strategy for Science, Technology, and Innovation (STISA-24) in 2014. Its implementation is going through a Monitoring and Evaluation (M\&E) phase which requires, among other

1 African Economic Outlook (2019), www.afdb.org/fileadmin/uploads/afdb/Documents/ Publications/2019AEO/AEO_2019-EN.pdf.

2 www.un.org/en/development/desa/population/publications/pdf/trends/Population2030.pdf. 
things, an inclusive set of metrics that gauge the transfer of knowledge between various actors in order to reinforce the M\&E relevance for facilitating evidence-based, transparent, and accountable decision making (Chux et al. 2018). This chapter discusses themes that are undoubtedly of use to the STISA M\&E processes. These are the basic metrics for non-IP-mediated knowledge transfer, metrics for policy and practices related to knowledge transfer activities, and metrics to gauge the costs and benefits of knowledge transfer.

However, STISA has embraced a broader concept of knowledge that includes formal or codified tacit knowledge as well as traditional or indigenous knowledge. Tacit knowledge needs to be understood well especially for service industries, which are becoming a vital source of income and employment in Africa. Yes, tacit knowledge is difficult to write down, visualize, or transfer from one person to another but it underpins several innovations in the service sector, as shown by the Community Innovation Survey (CIS) ${ }^{3}$ conducted in about thirty African countries. The compilation and sharing of lessons learnt and other experiences and stories could be used alongside the CIS questionnaire to capture tacit knowledge. However, traditional knowledge transfer will need its own family of metrics to measure its dynamics.

STISA was designed in a way that responds to the demand of STI from socioeconomic sectors by embedding STI in those sectors. It outlines the key priorities that countries in Africa should collectively address through a series of innovative programs and projects. In that manner, the strategy aims to position STI to contribute toward Africa's transition to a knowledge-based economy. This strategy requires buy-in from, and collaboration between, state and nonstate actors at various level of implementation. These include continental, regional, and national public institutions, the private sector, research institutions, and actors operating in the formal and informal sectors, as well as a significant cluster of multinational and development partners operating on the continent. In this complex environment, the set of metrics for knowledge transfer highlighted in the Arundel and Es-Sadki chapter will play a critical role if STISA seeks societal-led knowledge transfer in extending Africa's development toward a knowledge-based economy.

The metrics for non-IP-mediated knowledge transfer need to be expanded and adapted to collate relevant data that will feed the analysis of the critical factors that underpin tacit knowledge. The CIS referred to

3 African Innovation Outlook Series I (2014) \& II, 2014. 
above indicates that innovation is a connected activity. Innovative firms in Africa collaborate and their first choice of collaborator is the client or customer. Thus, knowledge transfer happens and needs to be measured. This is a link that needs to be expanded for additional data collection regarding tacit knowledge. Finally, there is a need to establish a consensus on a framework to connect the informal economy, innovation, and intellectual property to round up the measurement agenda for STISA as far as "moving the continent towards a knowledge-based economy" is concerned. As a matter of fact, the informal sector plays a major role in the national economies, as measured by the share of its contribution to GDP. This is estimated to be between 25 and 45 percent, and its contribution to employment ranges from 3 percent to 90 percent. In this context, both African Innovation Outlook series pointed to several areas that need further research, including the definition of comparable indicators for policy purposes, understanding how innovation takes place in the informal economy, and how knowledge is passed between generations, and the barriers, incentives, and linkages between the informal and formal sector dynamics.

\section{Measurement Challenges for New Data Dynamics in Africa}

New technologies can help African countries harness new sources of data and indicators by exploring knowledge transfer mechanisms between socioeconomic actors operating at the time of the Fourth Industrial Revolution (4IR).

The advent of the African Continental Free Trade Agreement (AfCFTA) would, in its optimal operational phase, transform the continent into a single market of a billion people with a combined GDP estimated to reach USD 2.5 trillion. ${ }^{4}$ The AfCFTA was signed in 2018 by the African countries. In this context, public policies, especially those related to the digital divide, trade regulations, and tariffs, ought to be amended or transformed to support free movement of capital and to sustain the single continental market for goods and services.

Other interesting advances to note concern the regional and continental dialogues that are taking place in the areas related to the 4IR. For instance, at their meeting in September 2017, ministers responsible for information and communication technology (ICT) of the Southern

4 www.un.org/africarenewal/magazine/august-november-2018/africa-set-massive-freetrade-area. 
African Development Community (SADC) noted that their region is on the brink of a technological revolution that will fundamentally alter the way people live, work, and relate to one another, and, in this regard, they signed the Declaration on the Fourth Industrial Revolution to guide the development of regional programs and projects. ${ }^{5}$ The Declaration is a commitment to preparing SADC for the Fourth Industrial Revolution through the use of ICT. The Declaration also calls for harmonization of enabling digital policies and universal access to critical broadband infrastructure.

The continent has also been home to several innovations, including the digital payment system (M-PESA), made in Kenya - which is gradually boosting many services ranging from e-commerce to healthcare and transportation. Blockchain technology has been trialed in areas of microlending. The Africa blockchain conference, which was due to be held in March 2020, offers an opportunity for African researchers to explore how this technology might simplify and streamline systems and processes across various industries. The question that begs for an answer remains: How to measure? What are the appropriate and relevant metrics to measure knowledge transfer?

Measuring knowledge transfer in this new era will require defining new sources of data. As pointed out by Arundel and Es-Sadki, big data and web-scraping would be the technologies for continental institutions like AOSTI to explore and invest in by continental institutions like the African Observatory for Science, Technology, and Innovation (AOSTI).

\section{Conclusion}

The production of the African Innovation Outlook Series, including the bibliometrics series produced by AOSTI, shows the importance of better understanding the transfer and application of knowledge between firms, policymaking institutions, research institutions, and the public. Yet the African measurement community needs to invest in metrics related to knowledge activities, especially knowledge transfer. The chapter by Arundel and Es-Sadki is an important step that needs to be extended by collecting more African examples. It is also important to gain knowledge on big data, blockchain, artificial intelligence, and the Internet of Things through case studies across impact sectors in the African contexts highlightedhere.

5 www.sadc.int/files/6315/6115/1098/Statement_ET-STI_21_June_2019_final.pdf. 


\section{References}

African Union (2014). Science, Technology and Innovation Strategy for Africa (STISA2024). 2014. https://au.int/sites/default/files/newsevents/workingdocuments/ 33178-wd-stisa-english_-_final.pdf.

Chux, C., K.P. Mawoko, and A. Konte (2018). Evaluating Science, Technology and Innovation Policies in Africa: Insights from the Science, Technology, and Innovation Strategy for Africa 2024 (STISA-2024). African Observatory for Science, Technology and Innovation (AOSTI) policy brief. 